\title{
Concentrating PV/T Hybrid System for Simultaneous Electricity and Usable Heat Generation: A Review
}

\author{
Longzhou Zhang, Dengwei Jing, Liang Zhao, Jinjia Wei, and Liejin Guo \\ International Research Center for Renewable Energy, State Key Laboratory of Multiphase Flow in Power Engineering, \\ Xi'an Jiaotong University, Xi'an 710049, China \\ Correspondence should be addressed to Dengwei Jing, dwjing@mail.xjtu.edu.cn
}

Received 18 April 2012; Revised 14 June 2012; Accepted 22 July 2012

Academic Editor: Christophe Menezo

Copyright ( $\odot 2012$ Longzhou Zhang et al. This is an open access article distributed under the Creative Commons Attribution License, which permits unrestricted use, distribution, and reproduction in any medium, provided the original work is properly cited.

Photovoltaic (PV) power generation is one of the attractive choices for efficient utilization of solar energy. Considering that the efficiency and cost of PV cells cannot be significantly improved in near future, a relatively cheap concentrator to replace part of the expensive solar cells could be used. The photovoltaic thermal hybrid system (PV/T), combining active cooling with thermal electricity and providing both electricity and usable heat, can enhance the total efficiency of the system with reduced cell area. The effect of nonuniform light distribution and the heat dissipation on the performance of concentrating PV/T was discussed. Total utilization of solar light by spectral beam splitting technology was also introduced. In the last part, we proposed an integrated compound parabolic collector (CPC) plate with low precision solar tracking, ensuring effective collection of solar light with a significantly lowered cost. With the combination of beam splitting of solar spectrum, use of film solar cell, and active liquid cooling, efficient and full spectrum conversion of solar light to electricity and heat, in a low cost way, might be realized. The paper may offer a general guide to those who are interested in the development of low cost concentrating PV/T hybrid system.

\section{Introduction}

Solar energy is the richest renewable energy on Earth. It is pollutant-free, widely scattered, and inexhaustible. However, solar energy is of low density, dispersed, unstable, and discontinuous. Currently, methods for solar energy conversion mainly include solar hydrogen production, solar thermal power generation, and photovoltaic (PV) power generation. Compared with solar thermal power generation, PV power generation can realize direct photoelectrical conversion, leaving out the intermediate energy conversion step. Thus, its generating efficiency is not restrained by the Carnot cycle. Moreover, because of its less demand for solar radiation intensity, $\mathrm{PV}$ power generation has more extensive applicability and is the best choice for the distributed energy supply, such as in a small-scale households $[1,2]$. Two urgent problems need to be addressed in solar PV application, that is, the high cost of PV power generation and the relatively low photoelectric conversion efficiency. Currently, the industrial production of crystalline silicon solar cell conversion efficiency is approximately $16 \%$ to $17 \%$, the highest being only about $22 \%$.

Under the circumstances in which the efficiency and cost of PV cells cannot be significantly improved in a short period, the following two approaches can be adopted to promote the large-scale commercialization of the technology. (1) The highly efficient and low-cost concentration technology should be developed. In this case, the unit area incident light intensity of the PV cell should be improved to reduce the cell area required for the given generated power. A relatively cheap concentrator as a replacement for the part of an expensive solar cell could be used. (2) When sunlight reaches the PV cell, incident photon energy should be converted into electric energy only. When the incident photon energy is more than the band gap of the semiconducting material, the extra energy not only cannot be converted into electric energy but into wasted heat, which severely affects the photoelectric conversion efficiency [3]. Experimental and theoretical researches on these two crucial issues have been conducted. 


\section{Traditional Concentrating PV System}

The concentrator is an important component for concentrating PV systems. It is classified according to optical principle, concentrator types, and geometric concentration ratio. The line focus solar concentrator includes the lens, parabolic trough, and line focusing parabolic collector. The point focusing concentrator is called the axial concentrator. The concentrator lens or reflectors of this type of concentrator are on the same optical axis of the solar cell [4]. According to the geometric concentration ratio, the concentrator can be divided into a low-concentration system and a highconcentration system with a solar tracking. Although the concentration ratio of the low-concentration system is not high, the scattered radiation can be used without a solar tracking and be applied in the area with inadequate direct radiation. Generally, if the concentration ratio is more than 10 , the system can only use direct sunlight. As a result, the tracking system must be adopted.

Since the mid-1970s, with a concentration ratio of 50 and efficiency of $12.7 \%$, the first concentrating PV system was developed in Sandia National Laboratories in US. This technology has rapidly developed. In its earlier stage, the Fresnel lens was superior in property to other light concentrating devices. The passive cooling was also feasible with the high-concentration ratio, and the application of the diamond plate and copper heat sink promoted the development of the technology. The schematic diagram of the PV concentrator Fresnel lens is shown in Figure 1.

The solar PV power generation has benefited from the improvement of the Fresnel lens. For instance, the $20 \mathrm{~kW}$ point focusing Fresnel lens array was developed by Amonix and SunPower after 15 years of continuous research [5]. Ryu et al. [6] designed the modularized and microfaceted Fresnel lens with a moderate concentration ratio, bringing about efficient superposition and finally uniform distribution of incident solar flux. They also formulated a mathematical model to solve the distribution of the energy flux on PV panel and the collecting efficiency. The calculation indicates that the nonuniformity of energy distribution remains within $20 \%$. Under the condition of the lower-middle concentration ratios (50 times), the radiation transmittance is more than $70 \%$. Andreev et al. [7] designed the fullglass high-concentration ratio PV modular with secondconcentration lens of small aperture between the Fresnel lens and cells, which further improve the light concentration. The concentrating ratio of the concentrator system reaches 1000 , and the size of PV is only $1.2 \mathrm{~mm}$. It is convenient to scaleup the module and improve its weathering resistance. Rosell et al. [8] designed a line focused PV system with Fresnel lens. It was found that heat conduction between solar cells and heat absorber is crucial to the energy efficiency of the whole system. Recently, Wu et al. [9] conducted extensive indoor experimental investigation on the heat loss from a point focus Fresnel lens PV concentrator with a concentration ratio of $100 \times$ under a range of simulated solar radiation intensities between 200 and $1000 \mathrm{~W} / \mathrm{m}^{2}$, different ambient air temperatures, and natural and forced convection. It was found that the solar cell temperature

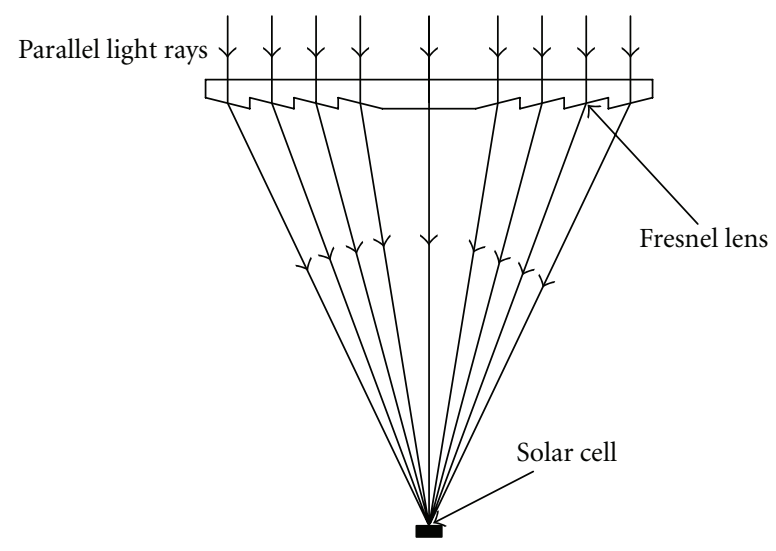

FIGURE 1: Schematic illustration of PV concentrator Fresnel lens [5].

increased proportionally with the increase in simulated solar radiation for all experimental tests, indicating that conductive and convective heat transfer were significantly larger than the long wave radiative heat transfer within and from the system.

The Fresnel lens belongs to the refractive concentrator, leading to a small light aperture and hence a small battery plate area. The reflecting concentrator can overcome this weakness. The point focused rotating parabolic concentrators and the line focused trough-type concentrators PV systems are mostly employed in the reflective PV concentrator. A representative $10 \mathrm{~m}^{2}$ trough concentrator PV with geometric concentration ratio of 30.8 is shown in the left part of Figure 2 [10].

The trough-type PV system caused the solar cell to be between the sun and the reflecting surface. The solar cell is always below the reflective parabolic focal line where the rays are inevitably sheltered, thus leading to optical nonuniform flux distribution. In recent years, the butterfly-shaped PV concentrator has been developed. A row of plane mirrors is installed at its bottom. A solar cell module is fixed on its top, reducing the shelter of sunlight by the PV devices to a certain extent. Xu et al. [11] developed a butterfly-shaped PV concentrator, as shown by the right part of Figure 2 . The sunlight reflected through the mirror plane uniformly reaches the solar cell array of the corresponding side, with its concentrations varying between 2 and 12 times.

A multidisc parabolic concentrator PV with a dual-axis tracking system was developed by NREL of US. This disctype concentrator system includes 16 reflecting surfaces, with each surface containing 76 reflecting blocks. The mirror area of the system covers $113 \mathrm{~m}^{2}$ with a highly precise tracking system and a concentration ratio of 250 [12]. The well-known Spanish solar energy research institution PSA developed a multidisc PV concentrator demonstration system with a concentration ratio of 2000 . It includes the heliostat, optical grating, multidisc concentrator, and PV board and can simultaneously test the PV response to the direct solar radiation and thermal flux distribution [13].

In terms of the low concentration PV system, Solanki et al. [14] integrated the monocrystalline silicon solar cell into the V-type reflection trough made of aluminum foil, 


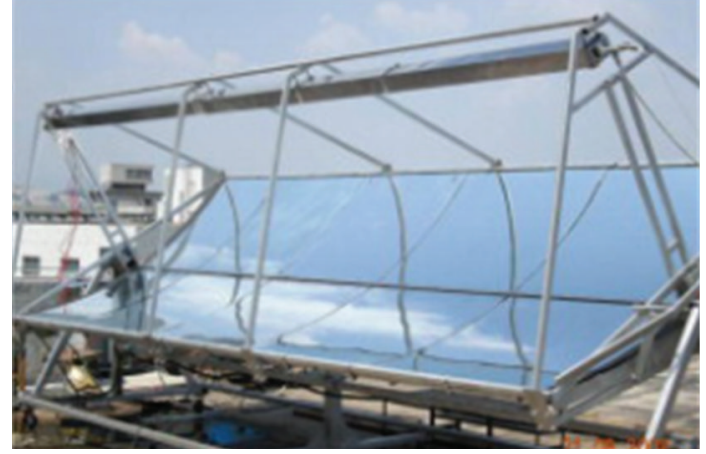

(a)

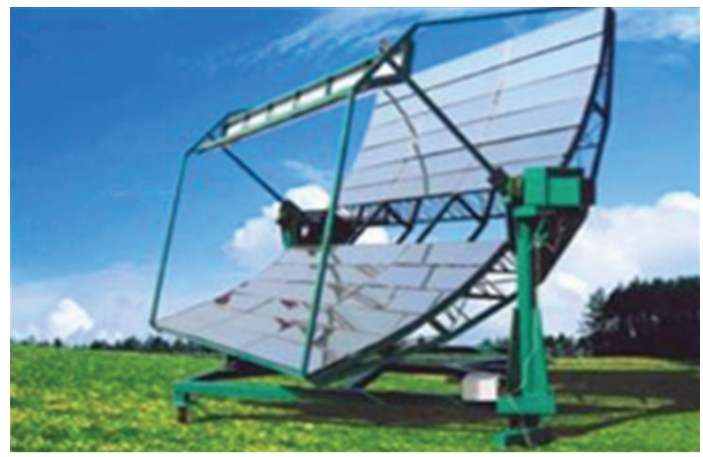

(b)

FIGURE 2: Representative trough (left hand) [10] and butterfly-shaped (right hand) concentration PV system [11].

which not only plays the role of reflection and concentration but also contributes to the heat dissipating capacity. However, its concentration ratio is only 2. The working temperature of the system is approximately the same as the one required for the nonconcentration condition. As a result, the efficient control of the temperature and the increase in the current density improve the output of the open circuit voltage. However, this type of concentrator not only has a low concentration ratio but also nonuniform radiation distribution and severe loss of reflection. In the different types of concentrating PV systems mentioned above, with the exception of the low-concentration V-type reflecting trough, the Fresnel lens, trough-type concentrator, butterflyshaped PV concentrator, and multidisc parabolical mirror concentrator systems all need high-precision single-axis or dual-axis tracking, which uses only direct solar radiation and diffuse reflections (generally occupying 30\% of the solar spectrum) which are unavailable for such tracking system.

Compound parabolic collector (CPC) is a nonimaging collector designed according to the marginal optical principle. Theoretically, all the incoming light with incident angle smaller than the maximum half acceptance angle $(\theta)$ could be line focused on the absorber. Both direct and diffuse portion of the solar radiation could be utilized. The performance of CPC is very close to that of the ideal concentrator. If the CPC concentrator adopts the stationary installation, the largest acceptance angle would be $30^{\circ}$. In this case, the concentration ratio would be less than 2 [15]. If the installation is in the east-west direction, and the tilt angle is adjustable, the largest acceptance angle would be less than $30^{\circ}$, with the concentration ratio as high as approximately 4 [16]. Nilsson et al. [17] designed a compound PV system with an asymmetric CPC and conducted investigation on the output performance of the system in different seasons and sunlight with MINSUN program. The research indicates that the total annual reflecting power of $\mathrm{CPC}$ with the reflective materials of anodic aluminum oxide and steel aluminum, respectively, is very close. When the PV panel faces the CPC light aperture, the output of the electric power per unit area is $205 \mathrm{Kwh} /\left(\mathrm{m}^{2}\right.$ cell area), and the output of the thermal energy in the cooling system is $145 \mathrm{kWh} / \mathrm{m}^{2}$. Hatwaambo et al. [18] conducted research on the concentration PV system based on a single CPC and investigated the influence of the light incident angle and the tilt of CPC angle on the output performance of PV. Radiation flux distribution on PV surface was simulated by ray tracing. The theoretical model was validated by experimental measurement.

\section{Cooling of Concentrating PV System}

For different types of concentration PV at a fixed temperature, the general tendency of the change in the solar cell efficiency corresponds to the change in the concentration ratio. The cell efficiency increases with the increase in the concentration ratio at the low-concentration ratio and decreases with the increase in the concentration ratio at the high-concentration ratio. Under the condition of the given output power, the tandem-type cell may increase the voltage output and reduce the ohmic loss. However, the nonuniformity of light intensity distribution and the poor heat dissipation leads to overheat of the cell panel, affecting the current output of the whole cell array. This is the called "the current matching problem." The effective PV cell cooling or the appropriate design of the concentrator may lessen the consumption of the parasitic power [19].

Hein et al. [21] demonstrated that the distribution of light intensity produced by the parabolic trough concentrator is similar to a Gaussian curve. Compared to uniform illumination, both the open-circuit voltage and efficiency of the concentrator PV cell would decrease. The decrease could be aggravated when the peak intensity of light distribution is increased. This decrease may lead to a serious nonuniform flux distribution. Currently, tandemtype module was adopted by most polycrystalline silicon solar cells and the current output of each cell module is equal in this case. For such type of module, the low light intensity in some areas (corresponding to the smaller light current) greatly limits the general current output of the whole PV system. Therefore, in case one or more cells are shaded, for example, like in Figure 3(a), module performance will be limited by the output of these cells. For the thin film module in Figure 3(b) however, all cells span across the full length of the module. The current generation will therefore be equally affected for each cell, and the power output is only reduced in proportion to the shaded area [20]. 


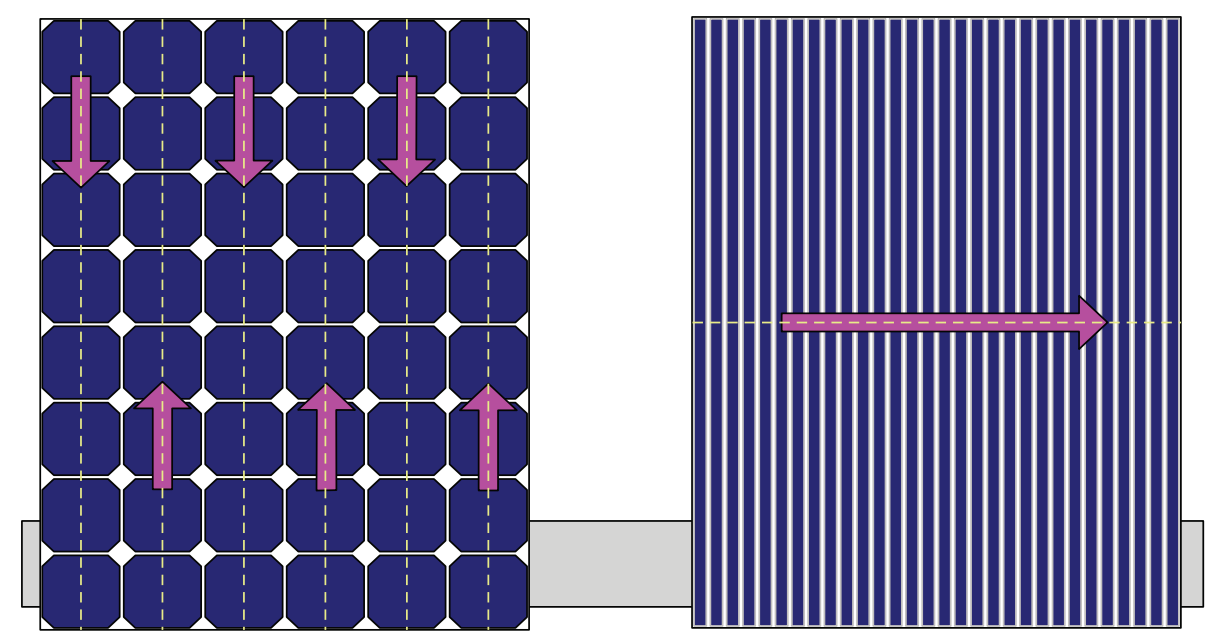

(a)

(b)

FIGURE 3: Schematic drawing of a conventional c-Si module (a) and a thin film module (b) under nonuniform illumination. For each module, the order in which the cells are series connected is indicated with a dashed line [20].

Under the high concentration ratios, for instance, the multidisc concentrator with 150 concentration ratios, the PV system has a severe cooling problem. Such PV system requires active cooling and a lower thermal resistance [2224]. To some extent, nonuniform flux distribution even exists in the CPC. For the CPC with a concentration ratio of 3 to 5 , the concentration ratio in some points may reach 50 . The nonuniform distribution of light intensity and poor heat dissipating may cause temperature gradient, especially in the high-concentrating PV. Recent research shows that the "Thomson effect" produced by the interaction between the temperature gradient and the electrical current may either improve or lower the power output of the cell [25], that is, when the current passes through the conductor with the temperature gradient, heat exchanges could take place absorbing or dissipating heat. Therefore, in the process of numerical simulation, the Thomson effect has to be considered.

As regards the cooling of the PV cell panel, except for the usual air or water cooling measures, techniques such as heat tube cooling, jet flow, microchannel cooling, and liquid immersion cooling has been investigated [26-28]. The liquid immersion cooling may effectively eradicate the contact thermal resistance caused by the traditional PV back cooling, thus improving cell efficiency. However, the study reveals that despite the quite uniform distribution of the temperature in the system, the long time immersion in the deionized water may also lower the $I-V$ output performance of PV.

\section{The Photovoltaic Thermal Hybrid System (PV/T)}

The cooling modes mentioned above not only have a poor heat dissipating effect, but they also generate waste heat. The photovoltaic thermal hybrid system (PV/T) combining active cooling with thermal electricity provides both electricity and usable heat which can enhance total efficiency of the system. The area covered required for $\mathrm{PV} / \mathrm{T}$ is also reduced compared to traditional PV. These factors are especially beneficial to the distributed energy supply.

For the nonconcentration, plate PV/T system as developed by Sandnes and Rekstad [29], the silicon PV cell is attached to the flat plate surface that is covered with the glass. For such system, the experiment was conducted mainly at a low water temperature. Saitoh et al. [30] developed a PV/T collector by attaching the silicon PV cell to the aluminum plate, whose back is made of copper tubing. The thermal output performance of the system was tested using salt water as working medium. Zakharchenko et al. [31] proposed a PV/T collector with its surface covered with a black PVC absorber, and the collector itself can combine with different PV cells. They found that when the area of the PV cell is smaller than that of the collector plate, and that the cell is located at the cooling water inlet, a better cooling effect and higher thermal efficiency could be achieved. Theoretically, the total energy efficiency of the PV/T system may reach $60 \%-80 \%$ [32]. Dupeyrat et al. proposed a real size PV/T module tested at Fraunhofer solar test facilities. The PV/T module showed a total efficiency of above $87 \%$ (79\% thermal efficiency plus $8.7 \%$ electrical efficiency, based on the absorber area) [33]. An experimental flat plate PV/T collector was built by the same group using the single package lamination method, focusing on an improved heat transfer between PV cells and cooling fluid and on improved optical performance. The thermal efficiency at zero reduced temperature was measured at $79 \%$ under PV operation with a corresponding electrical efficiency of $8.8 \%$, leading to a high overall efficiency of almost $88 \%$ [34].

Kostic et al. [35] studied the effect of reflectivity on the energy efficiency of a plate-type PV/T and optimized the installing position and tilt angle. The study shows that the reflection coefficient of the plate-type receiver made of aluminum plate and that of aluminum foil is almost the same. 
However, the reflecting surface made of aluminum foil enhanced the concentration intensity, thus improving the total thermoelectricity conversion efficiency.

The PV/T system with the parabolic trough concentrator (concentration is 37 times, and the peak light intensity in some areas is 100 times) was developed by Coventry [36]. It has thermal efficiency of $58 \%$, electrical efficiency of $11 \%$, and total energy conversion efficiency of $69 \%$. Wang et al. [37] constructed a trough-concentrating solar PV/T. Under the 10 times solar concentration, the monocrystalline silicon solar power could be increased by 5.05 times. Sun and Shi [38] analyzed the thermoelectric properties of the $\mathrm{PV} / \mathrm{T}$ system with a parabolic solar concentrator and radiating fin. They established a one-dimensional steadystate mathematical model of the heat transfer process inside the PV/T. They also conducted a numerical simulation of the heat transfer process and analyzed the air mass flow, incident light intensity, concentration ratio, ambient temperature, height of the upper channel, and effect of the fin parameters on air temperature, cell plate temperature, and thermal efficiency of the system.

Studies on the system with a low concentration of CPCbased PV/T have also been conducted. However, most of them have fixed CPCs or CPCs that could only be quarterly adjusted. These PV/T systems adopt simple air cooling or water cooling. For instance, Garg and Adhikari [39] studied a PV/T with CPC as the concentrator and air as the cooling medium. The parametric analysis showed that with the increase in the length of the collector, the amount of air flow or the surface covering ratio of the collector would greatly enhance the heat and electricity output properties, whereas the increase in the width of the air flow channel is not beneficial. Othman et al. [40] designed a CPCbased double channel solar air collector installed with heat conducting fins. The air passes through the upper channel containing the glass plate and the PV panels. The PV plate is directly heated by the sun. Air coming out of the upper channel flows out from the channel at the bottom, where the heat exchange of air in the direction of the PV may be enforced, improving the efficiency of the system. The authors simultaneously analyzed the heat transfer efficiency of the system by adopting the one-dimensional steady-state model.

Brogren et al. [41] introduced a water-cooled PV-thermal hybrid system with low concentrating aluminium compound parabolic concentrators, as shown in Figure 4. The system was installed at $60.5^{\circ} \mathrm{N} 17.4^{\circ} \mathrm{E}$ of Sweden. The following are the system parameters: $C=4$, the peak power output is $0.5 \mathrm{~kW}$, the corresponding annual electric power output of the solar cell in the unit area is $250 \mathrm{kWh}$, and the thermal output is $800 \mathrm{kWh}$. The optical efficiency was calculated to be 0.71 . The research also showed that the antireflection coating on the optimized glass plate and the improvement of the reflecting ratio of the reflecting material could improve the power output by approximately $20 \%$ [41]. It is worth noted here that most of CPC-based PV systems use very simple design either employing fixed installation or with periodical adjustment in a few months. The design will lead to significant variation under different solar azimuth (such as 9 a.m and 5 p.m. contrast), so the system output

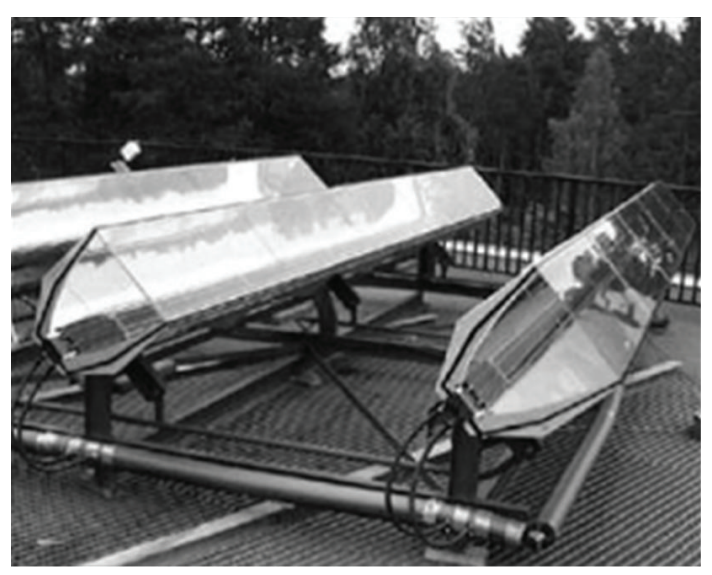

Figure 4: A representative PV-CPC is installed in Sweden $\left(60.58^{\circ} \mathrm{N}\right.$, $17.48^{\circ} \mathrm{E}$ ). The cooling water is flowing (from west to east) in copper pipes integrated in the aluminum fin on the backside of the $\mathrm{m}-\mathrm{Si}$ cells [38].

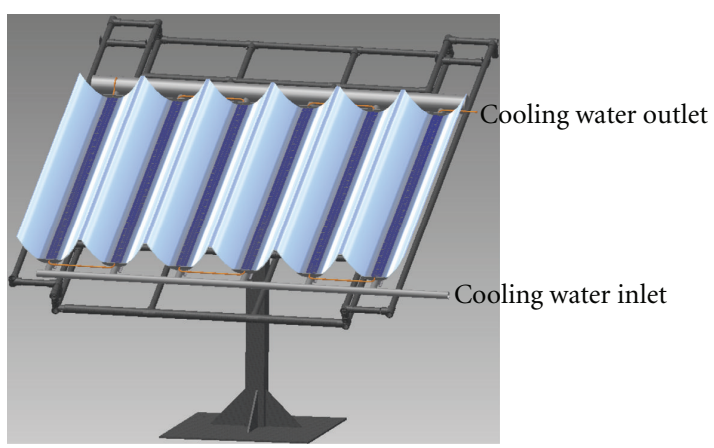

Figure 5: Our design of PV/T hybrid system composed of integrated CPC plate with low precision solar tracking.

would show great fluctuation in one working day. Here, we propose a new concept of integrated flat CPC plate for effective solar collection. As shown in Figure 5, the integrated CPC plate could be adjusted in two axes manually or by electric machinery. Such low precision solar tracking ensure effective collection of solar light with a significantly lower cost compared to traditional high-precision solar tracking. However, the total reception of solar irradiation in one day could be significantly enhanced. In fact, our such design of integrated CPC plate has been successfully applied to the solar-to-hydrogen conversion and the technique is therefore believed to be also applicable to concentrating PV/T [42, 43].

\section{Total Utilization of Solar Light by Spectral Beam Splitting Technology}

The studies previously mentioned all aimed to improve the energy utilization efficiency of the whole system from the perspective of active and passive heat dissipation from the PV panel itself. In recent years, the concept of effective utilization of solar light by spectral beam splitting technology was proposed [44]. In contrast to the traditional solar PV utilization, this method achieves the photo-electricity and 
thermal-electricity conversion by separately using the different parts of the solar spectrum. The thermal management problem in the traditional PV concentrator was effectively overcome by this method. Studies showed that the spectrum splitting PV/T hybrid system has several potential advantages over a PV-only system and it is especially suitable for working under high concentration conditions [45]. In such system, the thermal unit is no longer limited by the photoelectric unit, and the nanofluids directly absorbed solar radiation to achieve efficient photo-thermal conversion [46]. For instance, Jiang et al. [47] proposed such a PV/T design with a two-stage parabolic trough concentrator. A spectral splitting filter was added between the parabolic trough and the PV, filtering out the IR light. Based on the zero-dimensional optical model and the ray tracing method, the distribution of the energy flow was also analyzed.

Jiang et al. [48] achieved beam splitting with a 13-layer film and established a three-dimensional optical model by considering the solar angle. They studied the effect of the spectral beam splitting on the heat and electrical output properties of the semiparabolic trough concentrator in $\mathrm{PV} / \mathrm{T}$ system. The spectral distribution in the system and the solar flux density distribution on the PV cell surface were investigated. Calculation showed that the optical efficiency of the system under the AM1.5 solar spectrum is $58.7 \%$. The tilt angle of the cell should be optimized to achieve the uniform energy density for different concentrator apertures.

In terms of theoretical studies, Zhao et al. [49] conducted a numerical simulation of the absorption characteristics of the absorption medium, assuming the maximum passing through of the $200-800 \mathrm{~nm}$ and the maximum absorption of the $800-2000 \mathrm{~nm}$ solar spectrum. The simulation is based on the Lorentz-Drude model with damped oscillation. The derived expressions were validated by Kramers-Kronig conversion. The calculations indicated that the thermal unit could absorb $89 \%$ of the infrared and pass through $84 \%$ of visible light. If the upper flow rate is reduced, the outlet temperature may reach $74^{\circ} \mathrm{C}$.

\section{Conclusion and Perspective}

To sum up, concentration PV can be classified into three categories in accordance with the comprehensive utilization of electricity or heat. (1) The temperature-control mode concentrating PV system with high concentration ratios (e.g., the immersion mode). It usually maintained a high electrical efficiency with low working temperature of below $50^{\circ} \mathrm{C}$. It is unable to supply usable heat due to the small area of the cell unit. (2) The PV/T mode system, which uses PV as the major thermal supply, provides the usable heat at higher temperature such as $80^{\circ} \mathrm{C}$. However, the power output of the PV will often be affected. (3) The full spectrum utilization of solar energy, that is, by spectral beam splitting technologies. It lowers the working temperature of $\mathrm{PV}$, maintaining its high efficiency, and supplies the required thermal output due to its large PV surface area.

As described above, the current research on concentrating PV/T focuses mainly on the concentrators of Fresnel, trough-type, and butterfly-type, and so forth. The common weaknesses of these collectors are their high cost required by sun tracking. More importantly, these collectors cannot use the diffused solar light, which occupy a considerable part of the solar radiation and cover a large area of land. A few studies related to CPC concentrating PV/T system showed that CPC might be a good choice. However, most of these systems use very simple design of the CPC either employing fixed installation or with periodical adjustment in a few months. The design will lead to significant variation under different solar azimuth and therefore fluctuation in output. We proposed a PV system with integrated CPC plate as illustrated in Figure 5 to overcome these drawbacks. On the other hand, the maximal receiving and utilization of solar flux itself could be obtained by beam splitting of solar spectrum, such as by nanofluids. Combination of thin film solar cell to overcome nonuniform light distribution, active cooling for heat utilization and integrated CPC plate as solar collector, and efficient and full spectrum conversion of solar light to electricity and usable heat, in a low cost way, might be realized.

\section{Acknowledgments}

The authors gratefully acknowledge the financial support of the National Natural Science Foundation of China (no. 50821064, 20906074), National Basic Research Program of China (no. 2009CB220000) and 863 Program (no. 2012AA051501).

\section{References}

[1] V. Quaschning, "Technical and economical system comparison of photovoltaic and concentrating solar thermal power systems depending on annual global irradiation," Solar Energy, vol. 77, no. 2, pp. 171-178, 2004.

[2] H. A. Zondag, "Flat-plate PV-Thermal collectors and systems: a review," Renewable \& Sustainable Energy Reviews, vol. 12, no. 4, pp. 891-959, 2008.

[3] L. T. Kostić, T. M. Pavlović, and Z. T. Pavlović, "Optimal design of orientation of PV/T collector with reflectors," Applied Energy, vol. 87, no. 10, pp. 3023-3029, 2010.

[4] G. Zubi, J. L. Bernal-Agustín, and G. V. Fracastoro, "High concentration photovoltaic systems applying III-V cells," Renewable \& Sustainable Energy Reviews, vol. 13, no. 9, pp. 2645-2652, 2009.

[5] K. Ryu, J. G. Rhee, K. M. Park, and J. Kim, "Concept and design of modular Fresnel lenses for concentration solar PV system," Solar Energy, vol. 80, no. 12, pp. 1580-1587, 2006.

[6] V. Garboushian, D. Roubideaux, and S. W. Yoon, "Integrated high-concentration PV near-term alternative for low-cost large-scale solar electric power," Solar Energy Materials \& Solar Cells, vol. 47, no. 1-4, pp. 315-323, 1997.

[7] V. M. Andreev, V. A. Grilikhes, V. P. Khvostikov et al., "Concentrator PV modules and solar cells for TPV systems," Solar Energy Materials \& Solar Cells, vol. 84, no. 1-4, pp. 3-17, 2004.

[8] J. I. Rosell, X. Vallverdú, M. A. Lechón, and M. Ibáñez, “Design and simulation of a low concentrating photovoltaic/thermal system," Energy Conversion \& Management, vol. 46, no. 18-19, pp. 3034-3046, 2005. 
[9] Y. P. Wu, P. Eames, T. Mallick, and M. Sabry, "Experimental characterisation of a Fresnel lens photovoltaic concentrating system," Solar Energy, vol. 86, no. 1, pp. 430-440, 2012.

[10] M. Li, X. Ji, G. L. Li, Z. M. Yang, S. X. Wei, and L. L. Wang, "Performance investigation and optimization of the Trough Concentrating Photovoltaic/Thermal system," Solar Energy, vol. 85, no. 5, pp. 1028-1034, 2011.

[11] Z. L. Xu, J. D. Liu, P. F. Feng, D. P. Hou, J. Y. Zhang, and Y. M. Zhang, "Research on a butterfly concentrator for photovoltaic generation," Acta Energiae Solaris Sinica, vol. 28, no. 2, pp. 174-177, 2007.

[12] L. Zhu, R. F. Boehm, Y. P. Wang, C. Halford, and Y. Sun, "Water immersion cooling of PV cells in a high concentration system," Solar Energy Materials \& Solar Cells, vol. 95, no. 2, pp. 538$545,2011$.

[13] J. Fernández-Reche, I. Cañadas, M. Sánchez et al., "PSA Solar furnace: a facility for testing PV cells under concentrated solar radiation," Solar Energy Materials \& Solar Cells, vol. 90, no. 15, pp. 2480-2488, 2006.

[14] C. S. Solanki, C. S. Sangani, D. Gunashekar, and G. Antony, "Enhanced heat dissipation of V-trough PV modules for better performance," Solar Energy Materials \& Solar Cells, vol. 92, no. 12, pp. 1634-1638, 2008.

[15] M. J. Carvalho, M. Collares-Pereira, J. M. Gordon, and A. Rabl, "Truncation of CPC solar collectors and its effect on energy collection," Solar Energy, vol. 35, no. 5, pp. 393-399, 1985.

[16] M. Brogren, M. Rönnelid, and B. Karlsson, "PV-thermal hybrid low concentrating CPC module," in Proceedings of the 16th European Photovoltaic Solar Energy Conference and Exhibition, pp. 1-5, Glasgow, UK, May 2000.

[17] J. Nilsson, H. Håkansson, and B. Karlsson, "Electrical and thermal characterization of a PV-CPC hybrid," Solar Energy, vol. 81, no. 7, pp. 917-928, 2007.

[18] S. Hatwaambo, H. Hakansson, J. Nilsson, and B. Karlsson, "Angular characterization of low concentrating PV-CPC using low-cost reflectors," Solar Energy Materials and Solar Cells, vol. 92, no. 11, pp. 1347-1351, 2008.

[19] T. T. Chow, "A review on photovoltaic/thermal hybrid solar technology," Applied Energy, vol. 87, no. 2, pp. 365-379, 2010.

[20] J. Wennerberg, J. Kessler, J. Hedström, L. Stolt, B. Karlsson, and M. Rönnelid, "Thin film PV modules for lowconcentrating systems," Solar Energy, vol. 69, supplement 6, pp. 243-255, 2001.

[21] M. Hein, F. Dimroth, G. Siefer, and A. W. Bett, "Characterisation of a $300 \times$ photovoltaic concentrator system with one-axis tracking," Solar Energy Materials \& Solar Cells, vol. 75, no. 1-2, pp. 277-283, 2003.

[22] A. Royne, C. J. Dey, and D. R. Mills, "Cooling of photovoltaic cells under concentrated illumination: a critical review," Solar Energy Materials \& Solar Cells, vol. 86, no. 4, pp. 451-483, 2005.

[23] H. Yusof, M. Othman, B. Yatim, K. Sopian, M. Nazari, and A. Bakar, "Performance analysis of a double-pass photovoltaic/thermal (PV/T) solar collector with CPC and fins," Renewable Energy, vol. 30, no. 13, pp. 2005-2017, 2005.

[24] H. Singh and P. C. Eames, "A review of natural convective heat transfer correlations in rectangular cross-section cavities and their potential applications to compound parabolic concentrating (CPC) solar collector cavities," Applied Thermal Engineering, vol. 31, no. 14-15, pp. 2186-2196, 2011.

[25] N. Ari and A. Kribus, "Impact of the Thomson effect on concentrating photovoltaic cells," Solar Energy Materials \& Solar Cells, vol. 94, no. 8, pp. 1421-1425, 2010.
[26] M. Beccali, P. Finocchiaro, and B. Nocke, "Energy and economic assessment of desiccant cooling systems coupled with single glazed air and hybrid PV/thermal solar collectors for applications in hot and humid climate," Solar Energy, vol. 83 , no. 10, pp. 1828-1846, 2009.

[27] L. Zhu, R. F. Boehm, Y. Wang, C. Halford, and Y. Sun, "Water immersion cooling of PV cells in a high concentration system," Solar Energy Materials \& Solar Cells, vol. 95, no. 2, pp. 538545, 2011.

[28] A. Royne and C. J. Dey, "Design of a jet impingement cooling device for densely packed PV cells under high concentration," Solar Energy, vol. 81, no. 8, pp. 1014-1024, 2007.

[29] B. Sandnes and J. Rekstad, "A photovoltaic/thermal (PV/T) collector with a polymer absorber plate. Experimental study and analytical model," Solar Energy, vol. 72, no. 1, pp. 63-73, 2002.

[30] H. Saitoh, Y. Hamada, H. Kubota et al., "Field experiments and analyses on a hybrid solar collector," Applied Thermal Engineering, vol. 23, no. 16, pp. 2089-2105, 2003.

[31] R. Zakharchenko, L. Licea-Jiménez, S. A. Pérez-García et al., "Photovoltaic solar panel for a hybrid PV/thermal system," Solar Energy Materials \& Solar Cells, vol. 82, no. 1-2, pp. 253261, 2004.

[32] M. A. Hasan and K. Sumathy, "Photovoltaic thermal module concepts and their performance analysis: a review," Renewable \& Sustainable Energy Reviews, vol. 14, no. 7, pp. 1845-1859, 2010.

[33] P. Dupeyrat, C. Ménézo, H. Wirth, and M. Rommel, "Improvement of PV module optical properties for PVthermal hybrid collector application," Solar Energy Materials \& Solar Cells, vol. 95, no. 8, pp. 2028-2036, 2011.

[34] P. Dupeyrat, C. Ménézo, M. Rommel, and H. M. Henning, "Efficient single glazed flat plate photovoltaic-thermal hybrid collector for domestic hot water system," Solar Energy, vol. 85, no. 7, pp. 1457-1468, 2011.

[35] L. T. Kostic, T. M. Pavlovic, and Z. T. Pavlovic, "Influence of reflectance from flat aluminum concentrators on energy efficiency of PV/Thermal collector," Applied Energy, vol. 87, no. 2, pp. 410-416, 2010.

[36] J. S. Coventry, "Performance of a concentrating photovoltaic/thermal solar collector," Solar Energy, vol. 78, no. 2, pp. 211-222, 2005.

[37] L. L. Wang, M. Li, Z. Q. Yang et al., "The combined heat and power cycle with concentrating trough solar power," Acta Energiae Solaris Sinica, vol. 30, no. 8, pp. 1054-1057, 2009.

[38] J. Sun and M. H. Shi, "Performance analysis of a solar photovoltaic/thermal system with compound parabolic concentrator," Acta Energiae Solaris Sinica, vol. 30, no. 11, pp. 1513-1518, 2009.

[39] H. P. Garg and R. S. Adhikari, "Performance analysis of a hybrid photovoltaic/thermal (PV/T) collector with integrated CPC troughs," International Journal of Energy Research, vol. 23, no. 15, pp. 1295-1304, 1999.

[40] M. Y. H. Othman, B. Yatim, K. Sopian, and M. N. Abu Bakar, "Performance analysis of a double-pass photovoltaic/thermal (PV/T) solar collector with CPC and fins," Renewable Energy, vol. 30, no. 13, pp. 2005-2017, 2005.

[41] M. Brogren, P. Nostell, and B. Karlsson, "Optical efficiency of a PV-thermal hybrid CPC module for high latitudes," Solar Energy, vol. 69, supplement 6, pp. 173-185, 2000.

[42] D. W. Jing, X. H. Zhang, C. J. Xing, X. M. Zhang, and L. J. Guo, "Photocatalytic hydrogen production under direct solar light in a CPC based solar reactor: Reactor design and preliminary 
results," Energy Conversion \& Management, vol. 50, no. 12, pp. 2919-2926, 2009.

[43] L. J. Guo, "Advances in solar hydrogen technologies," in Solar $\&$ Alternative Energy, Proceedings of SPIE, April 2011.

[44] A. G. Imenes and D. R. Mills, "Spectral beam splitting technology for increased conversion efficiency in solar concentrating systems: a review," Solar Energy Materials and Solar Cells, vol. 84, no. 1-4, pp. 19-69, 2004.

[45] B. Fisher and J. Biddle, "Luminescent spectral splitting: efficient spatial division of solar spectrum at low concentration," Solar Energy Materials \& Solar Cells, vol. 95, no. 7, pp. 1741$1755,2011$.

[46] M. A. Hamdy and S. H. El-Hefnawi, "Effect of spectrally selective liquid absorption-filters on silicon solar-cells," Applied Energy, vol. 35, no. 3, pp. 177-188, 1990.

[47] S. L. Jiang, P. Hu, S. P. Mo, and Z. H. Chen, "Optical modeling for a two-stage parabolic trough concentrating photovoltaic/thermal system using spectral beam splitting technology," Solar Energy Materials \& Solar Cells, vol. 94, no. 10, pp. 1686-1696s, 2010.

[48] S. L. Jiang, Z. S. Chen, P. Hu, and S. P. Mo, "Performance analysis of semi-parabolic trough concentrating spectral beam splitting PV system," Journal of Engineering Thermophysics, vol. 30, no. 3, pp. 365-369, 2009.

[49] J. F. Zhao, Y. C. Song, W. H. Lam et al., "Solar radiation transfer and performance analysis of an optimum photovoltaic/thermal system," Energy Conversion \& Management, vol. 52, no. 2, pp. 1343-1353, 2011. 


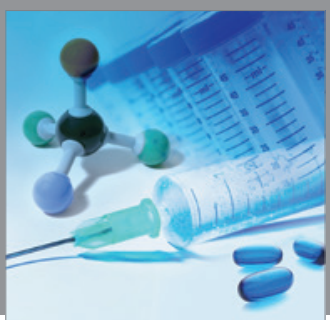

International Journal of

Medicinal Chemistry

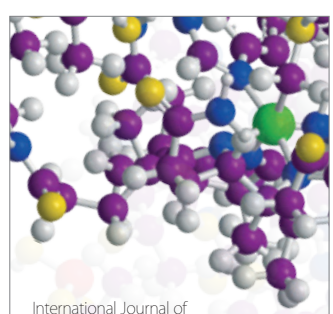

Carbohydrate Chemistry

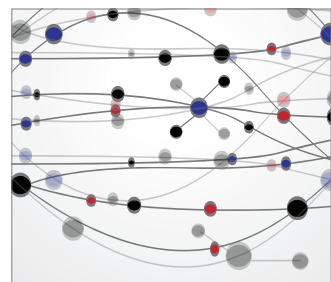

The Scientific World Journal
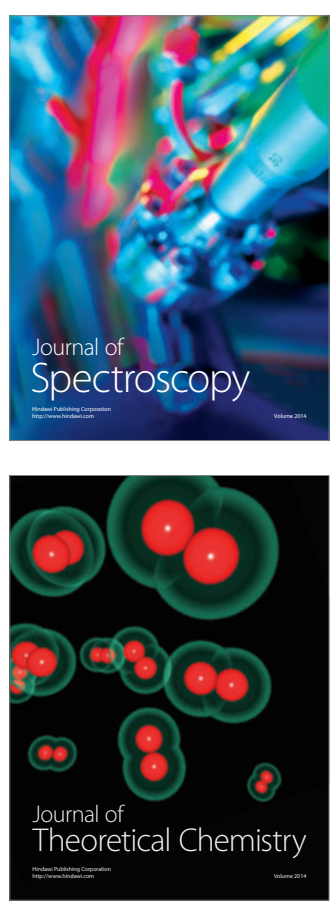
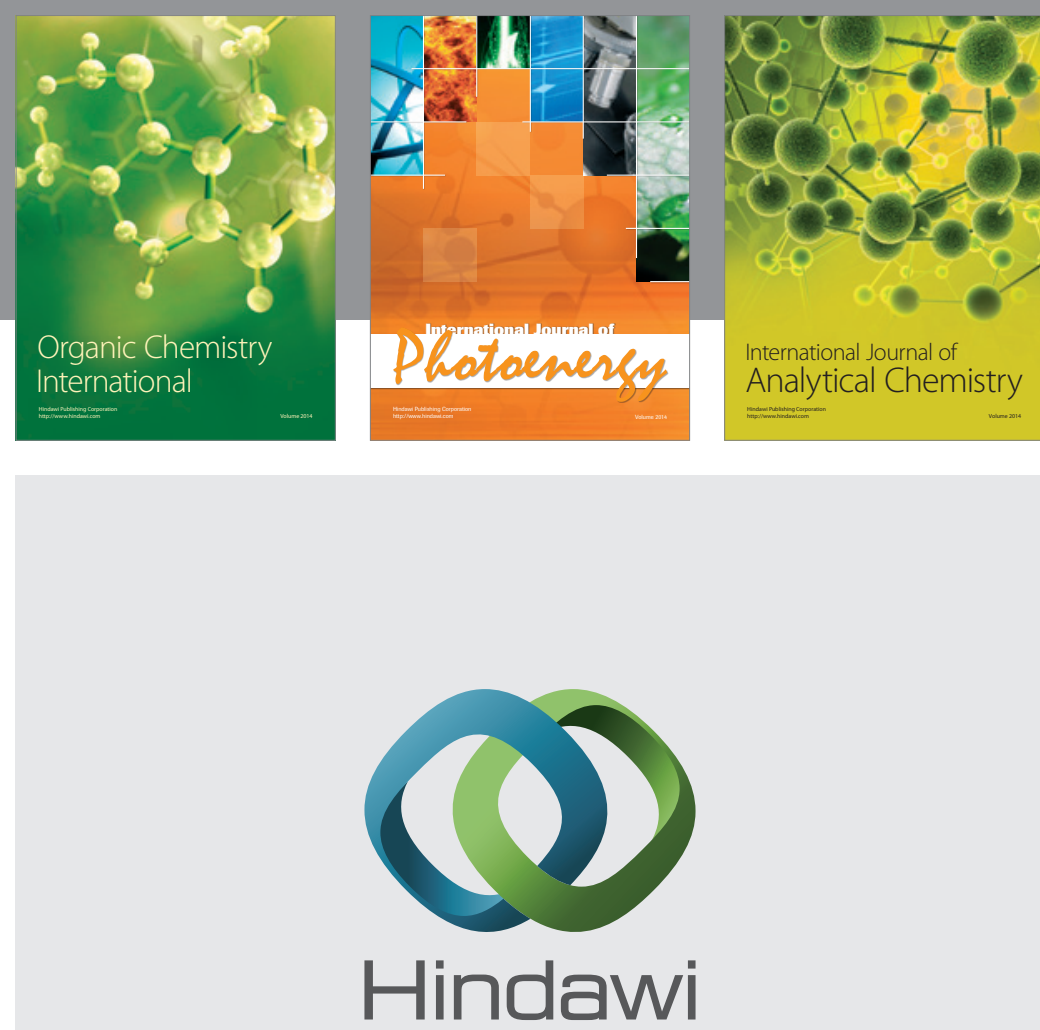

Submit your manuscripts at

http://www.hindawi.com
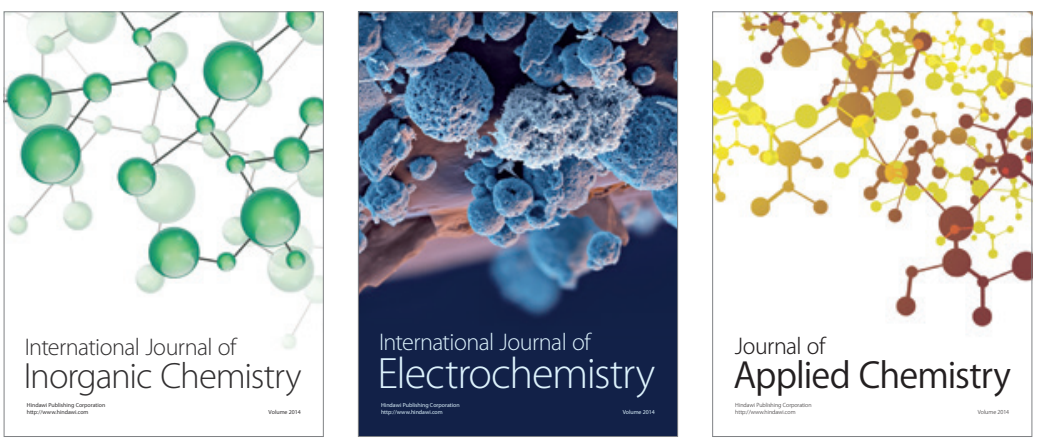

Journal of

Applied Chemistry
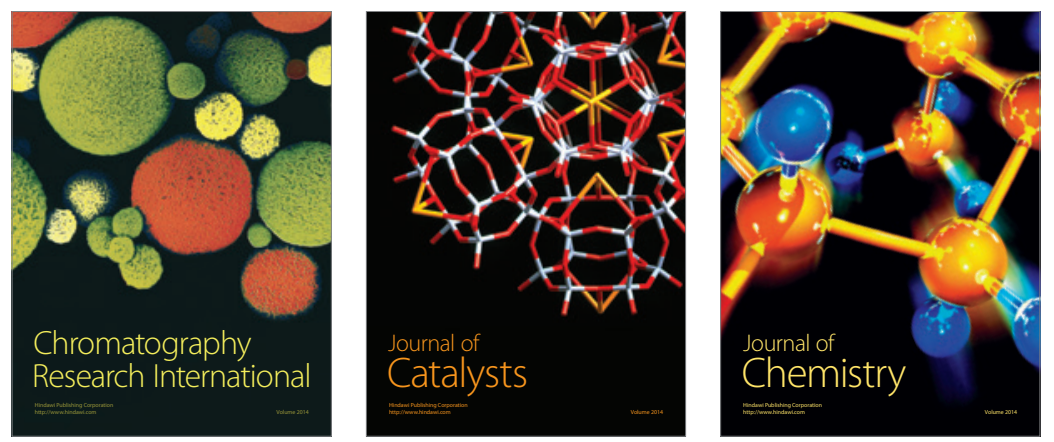
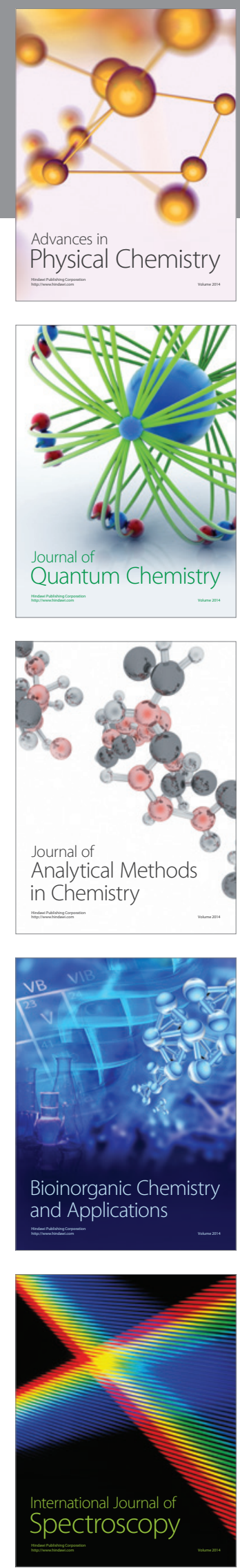